\title{
Ritual, teatro y performance en un culto al niño dios y al diablo. Las pastorelas de la región purépecha, Michoacán (México)
}

Rituel, représentation théâtrale et performance dans le culte à l'Enfant-Jésus et au Diable

Ritual, theater and performance in the worship of the Christ Child and the Devil. Christmas pageants in the P'urhépecha region of Michoacán, Mexico

\section{Elizabeth Araiza}

\section{OpenEdition \\ Journals}

Edición electrónica

URL: https://journals.openedition.org/jsa/13770

DOI: $10.4000 /$ jsa. 13770

ISSN: $1957-7842$

Editor

Société des américanistes

Edición impresa

Fecha de publicación: 17 septiembre 2014

Paginación: 163-190

ISSN: 0037-9174

Referencia electrónica

Elizabeth Araiza, «Ritual, teatro y performance en un culto al niño dios y al diablo. Las pastorelas de la región purépecha, Michoacán (México)», Journal de la Société des américanistes [En línea], 100-1 |

2014, Publicado el 01 enero 2016, consultado el 02 septiembre 2022. URL: http://

journals.openedition.org/jsa/13770 ; DOI: https://doi.org/10.4000/jsa.13770 


\title{
RITUAL, TEATRO Y PERFORMANCE EN UN CULTO AL NIÑO DIOS Y AL DIABLO. LAS PASTORELAS DE LA REGIÓN PURÉPECHA, MICHOACÁN (MÉXICO)
}

\author{
Elizabeth ARAIZA *
}

\begin{abstract}
La pastorela es, en principio, una representación viviente y dialogada que evoca el nacimiento de Jesucristo, el afán de los pastores por celebrar dicho acontecimiento y las tentativas del diablo por impedirlo. En la región purépecha, a lo que asistimos es a un evento en el que se imbrican varias modalidades de actuación, cada una de las cuales pone en marcha diferentes universos sensoriales y múltiples referentes. Este tipo de eventos ha sido estudiado como un género teatral cuando se realiza en contextos urbanos y como una modalidad de ritual cuando se lleva a cabo en el medio rural e indígena. La descripción de un caso en particular y la puesta en perspectiva de varias pastorelas entre los purépechas permitirá demostrar que, en este ejemplo, teatro y ritual se combinan sin que uno se sobreponga al otro, o le anteceda de manera evolutiva del tipo «del ritual al teatro ». El propósito es contribuir a la discusión sobre las dificultades que impone la definición de cada una y del conjunto de las modalidades de actuación: ritual, teatro, juego, performance, etc. [Palabras clave: pastorela, ritual, teatro, performance, purépechas.]
\end{abstract}

Rituel, représentation théâtrale et performance dans le culte à l'Enfant-Jésus et au Diable. Les pastorelas de la région purépecha, Michoacán, Mexique. La pastorela est, en principe, une représentation vivante et dialoguée qui évoque la naissance de Jésus, le zèle des bergers pour célébrer l'événement et les tentations du Diable pour empêcher cela. Dans la région purépecha, on assiste à une manifestation qui mêle différentes modalités de représentation, chacune faisant appel à des univers sensibles distincts et à des références multiples. Ce type de manifestation a été considéré comme relevant du genre théâtral en ville mais comme un rituel en contexte rural et indien. L'analyse d'un cas particulier avec mise en perspective de plusieurs pastorelas chez les Purépecha permet de démontrer que, dans notre exemple, théâtre et rituel se combinent sans que l'un l'emporte sur l'autre ou le précède dans une séquence de type « du rite à la représentation théâtrale ». Notre objectif est d'apporter des éléments à la discussion sur les difficultés qui découlent de la définition de chacune et de l'ensemble des modalités de

* El Colegio de Michoacán, av. Martínez de Navarrete n ${ }^{\circ}$ 505, Fracc. Las Fuentes, 59699, Zamora, Mich., México [elizabeth.araiza@colmich.edu.mx].

Journal de la Société des Américanistes, 2014, 100-1, pp. 163-190. C Société des Américanistes. 
la représentation (rituel, jeu théâtral, performance, etc.). [Mots-clés: pastorelas, rituel, représentation théâtrale, performance, purépecha.]

Ritual, theater and performance in the worship of the Christ Child and the Devil. Christmas pageants in the P'urhépecha region of Michoacán, Mexico. The Christmas pageant (pastorela) is, in principle, a living and dialogical representation that evokes the birth of Jesus, the zeal of the shepherds to celebrate that event, and the attempts by the Devil to impede them. In the P'urhépecha region we attended an event that interweaves various modalities of acting, each one of which brings to life distinct sensorial universes and multiple referents. When staged in urban contexts these events have been seen as a theatrical genre, but when performed in rural and indigenous areas they are considered a mode of ritual. Describing a specific case and putting various pastorelas staged by P'urhépechas into comparative perspective allows us to demonstrate that this event combines theater and ritual without one superimposing itself on the other or preceding it in an evolutionary sense (as in «from ritual to theater »). The point is to contribute to a discussion of the difficulties entailed in the definitions of the modalities of acting - ritual, theater, games, performance, etc. - both individually and as a whole. [Key words: Christmas pageants (pastorelas), ritual, theater, performance, P'urhépechas.]

En México la pastorela se asocia con una representación viviente y dialogada que evoca el nacimiento de Jesucristo, el peregrinar de María y José, las vicisitudes de los pastores en su afán de celebrar dicho acontecimiento y las tentativas del diablo por impedirlo; en ocasiones también la adoración de los Reyes Magos. Este pasaje evangélico, inculcado por los misioneros españoles desde el siglo XVI, ha sido adaptado constantemente en función de la historia socio-cultural del lugar donde se realiza. Actualmente existen incontables variantes. Para dar cuenta de éstas los investigadores (Romero Salinas 1984; Aracil, Ortiz y García 2004; Hijar Ornelas 2008) han establecido una distinción entre la pastorela rural e indígena o tradicional y la pastorela urbana o teatral. Esta última a su vez tiene una vertiente culta, basada en un texto de autor, escrito con un lenguaje refinado y con estructura compleja; es presentada en teatros de sala e interpretada por actores profesionales. Otra vertiente, caracterizada por un lenguaje propio de las clases populares urbanas, con estructura más sencilla, se presenta en las calles o patios de vecindades. Ambas vertientes adaptan aquel pasaje evangélico para mostrar acontecimientos locales, sean históricos o actuales, así como ciertos comportamientos típicos de los diferentes sectores de la sociedad. Así, por ejemplo, los pastores pueden cobrar la figura de mineros, estudiantes, sindicalistas, entre otros; el diablo, la de patrones, empresarios, gobernantes, comerciantes, narcos o policías. Los otros personajes - ermitaño, Ángel, María y José, Reyes Magos - adquieren igualmente rostros históricos o actuales para contribuir en la lucha del bien contra el mal. 
Las pastorelas tradicionales, según los estudios mencionados, se apegan más al pasaje evangélico, son realizadas en contextos rurales, campesinos e indígenas, en espacios al aire libre - el atrio de la iglesia o la plaza del pueblo; carecen de un texto escrito o bien éste se transmite por tradición oral, son dialogadas con un lenguaje corriente propio de los campesinos. Algunas variantes están desprovistas de diálogos y son más bien danzas. La variante de las pastorelas tradicionales que sin duda es más practicada, conocida y estudiada es aquella en la que figuran como personajes estelares unos pastores llamados Bato, Bartolo, Bras y Gila. Son personajes cómicos, con rasgos y comportamientos que caracterizan a los bobos, golosos, flojos, ingenuos e ignorantes. El diablo es presentado como un ser gracioso, ridiculizado y burlado constantemente por los pastores con ayuda del ermitaño y el ángel. La Virgen María y José aparecen en escena. Estas pastorelas pueden presentarse antes o después del periodo navideño, mientras que las teatrales-urbanas se restringen a las celebraciones navideñas (del 16 de diciembre al 6 de enero) y suelen durar en total una o dos horas.

No hay un poblado de Michoacán donde no se realice alguna de estas variantes. Sin embargo, las de la región purépecha presentan rasgos peculiares que dificultan clasificarlas sencillamente como teatrales o tradicionales. Cabe evocar tan sólo el caso de la pastorela de Comachuén, localidad perteneciente al municipio de Nahuatzen y situada en lo más alto de la Sierra (Figura 1), conservando un alto porcentaje de hablantes de lengua vernácula y que se autodefinen como tarascos o purépechas.

\section{Una pastorela en Comachú́n}

En Comachuén la pastorela se lleva a cabo el 24 de diciembre de cada año y comienza alrededor de las siete $u$ ocho de la noche. Un escenario, al modo del teatro italiano, con dimensiones considerables, en forma de palacio o templo, se instala en la plaza del pueblo para este efecto (Figura 2). Primero se escuchan unas notas profundamente melancólicas entonadas por la banda de música. Después aparece en escena un personaje con aspecto siniestro: tiene el rostro cubierto con un velo negro, viste con larga túnica y capa, en la cabeza lleva un tocado de papel con una pluma de pavo real. Así parece tener un cuerpo más grande que el común de la gente. Con voz ronca y fuerte, empleando una extraña entonación, recita una larga letanía: «¿Qué significa ese canto? ¿Qué me viene a contar? ¡Que mi sentencia devora y hace más cruel mi dolor, si por mi culpa perdí toda la grandeza de Dios! Dejadme pensar aquí en mi venganza feroz [...] ¡Pecado ven a mi auxilio, mira que te necesito! ¡Astucia, escucha mi grito, venid en rápido vuelo! ».

Enseguida aparecen uno a uno otros seis personajes con atuendo semejante (Figura 3). Alternándose profieren largos parlamentos que se acompañan con 


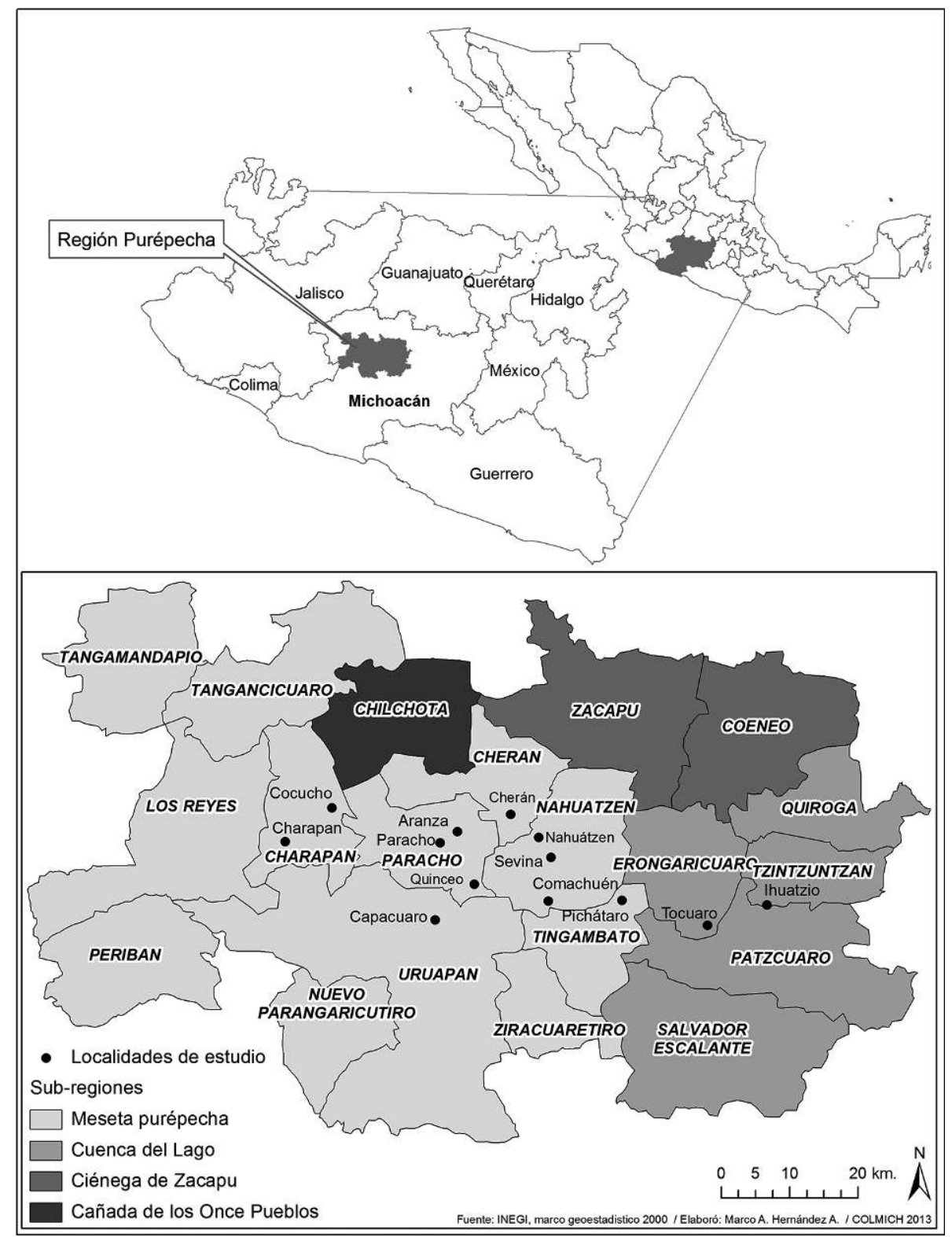

FIG. 1 - Ubicación de la zona de estudio. 
una tonada musical diferente cada vez. Discuten sobre las grandes interrogantes de la humanidad: « ¿En qué debemos creer? ¿Quién nos dice la verdad? ¿Cómo y hacia dónde debemos guiarnos, hacia lo bueno o lo no-bueno? » Después entran tres ángeles para hacer frente a aquellos seres aterradores. Los siete personajes de aspecto siniestro caen al suelo en signo de derrota.
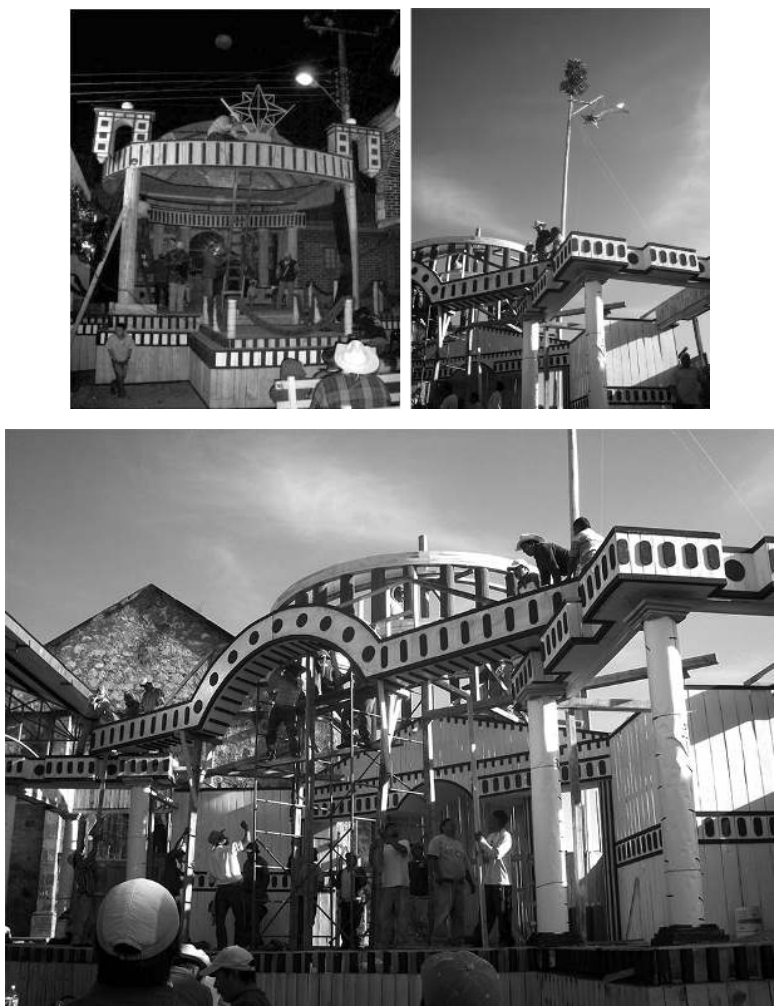

FIG. 2 - Escenario en forma de palacio o templo. Comachuén, 24 de diciembre de 2011. Arriba derecha y abajo Comachuén, 23 de diciembre de 2012 (fotos Araiza).

Pasadas dos o tres horas, aparecen en escena un ranchero y una ranchera, quienes, al escuchar la tonada que les es propia, ejecutan una danza; luego cantan una canción de cuna, se detienen y dialogan entre sí sobre cuestiones de la vida diaria, la riqueza, una vida de lujos y los problemas en la comunidad, en el país e incluso en el mundo; vuelven a danzar y salen de escena. Luego se presenta la danza de pastores y la de viejitos. Ya casi en la madrugada se anuncia la presentación de una « obra de teatro », un pasaje de la Biblia, está vez « Adán y 
Eva », adaptado para la escena. Las parejas de rancheros siguen luego desfilando una a una, bailan, cantan, dialogan entre sí, tomando por testigo al público.

Al mediodía del 25 de diciembre se realiza una procesión, llevando la imagen del Niño Dios y la de la Virgen María de la casa del carguero hacia la iglesia. Ahí se hace una misa y enseguida más danzas. Pastores y rancheros vuelven a bailar y a cantar en diferentes puntos del poblado. El día 26 por la tarde, unos personajes aparecen por todo el pueblo - en las calles, en la plaza, en los patios de las casas. Tienen el mismo aspecto siniestro de los que vimos primero, pero sus vestuarios y sus máscaras son diferentes. No son ya tres o siete, sino incontables; no profieren largos parlamentos, sino que emiten sonidos extraños como bramidos, brincan y bailan de manera frenética. Estos diablos continúan actuando hasta la noche del 27 de diciembre.

\section{El problema}

Lo que acabamos de describir de forma resumida es un caso particular y ciertamente habrá tantas variantes como poblados purépechas. Sin embargo debemos esforzarnos por alcanzar una visión global. Así observaremos que la mayoría de estos eventos se basan en un texto escrito en forma dialogada, en prosa o, más comúnmente, en verso - incluso en octosílabos. De ahí que se les denomine « coloquios », en referencia al género literario: una conversación entre dos o más personas y/o la discusión de un asunto. Los coloquios, en nuestra área de estudio, se llevan a cabo durante diciembre, enero y febrero. Contrastando con las caracterizaciones antes mencionadas, resalta que los pastores ocupan un lugar secundario, comparado con el de otros personajes, por ejemplo los rancheros (Araiza 2013, pp. 181-218). San José, el Niño Dios y la Virgen María no aparecen. No hay sólo uno sino tres, siete o nueve diablos representados bajo una extraña apariencia (Figura 3); y emergen decenas e incluso cientos de diablos adoptando una variedad de formas y realizando actos que remiten a múltiples referentes. Los diablos principales no llevan un traje rojo muy ceñido al cuerpo, ni tienen dos cuernos pequeños en la frente, una cola muy larga y un tridente en la mano, tal como aparecen en las pastorelas teatrales-urbanas. Tampoco aparecen bajo figuras similares, por ejemplo, a las de los típicos diablos de Ocumicho (Figura 4), o bien a las que los purépechas describen en sus narraciones orales ${ }^{1}$. En definitiva, el diablo de pastorela no es una representación escénica de las figurillas de barro, de los mitos y leyendas o de los testimonios de la aparición o encuentro con dicho personaje en la vida ordinaria ${ }^{2}$. 


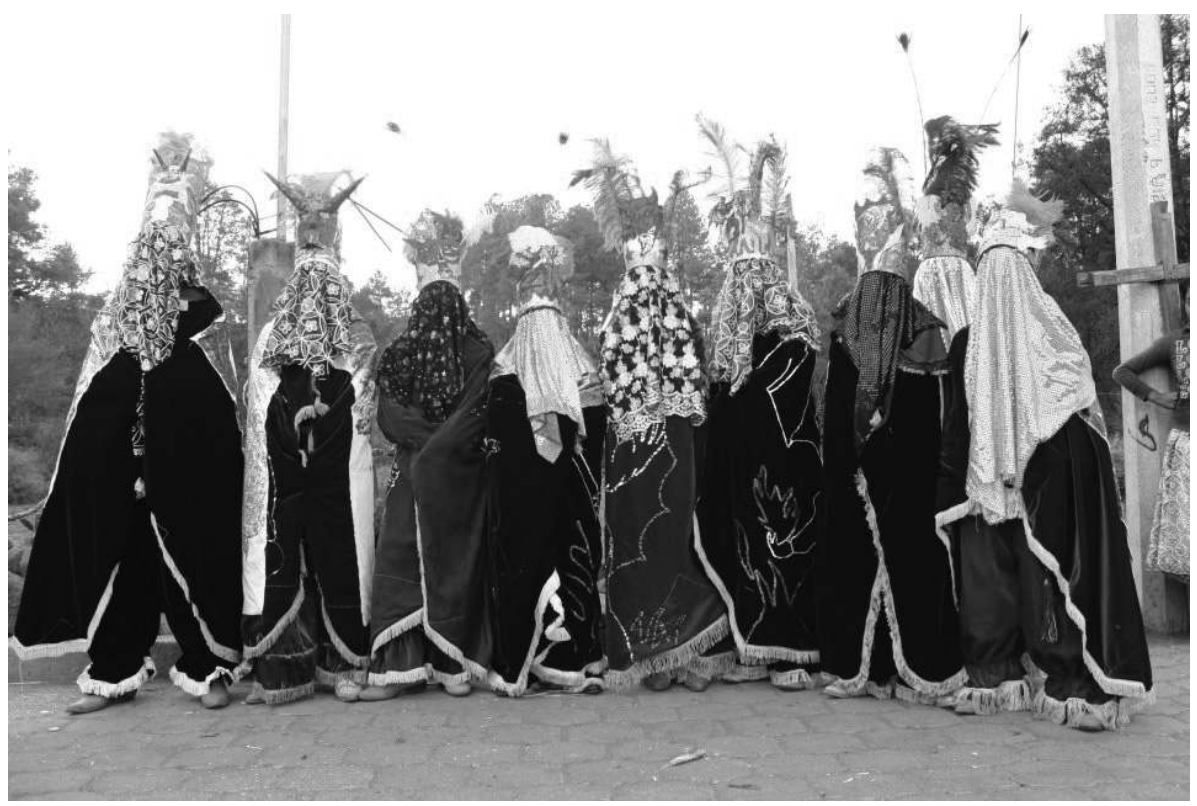

FIG. 3 - Luzbeles en la pastorela de Turicuaro (diciembre de 2012; foto Estrada Serafín).
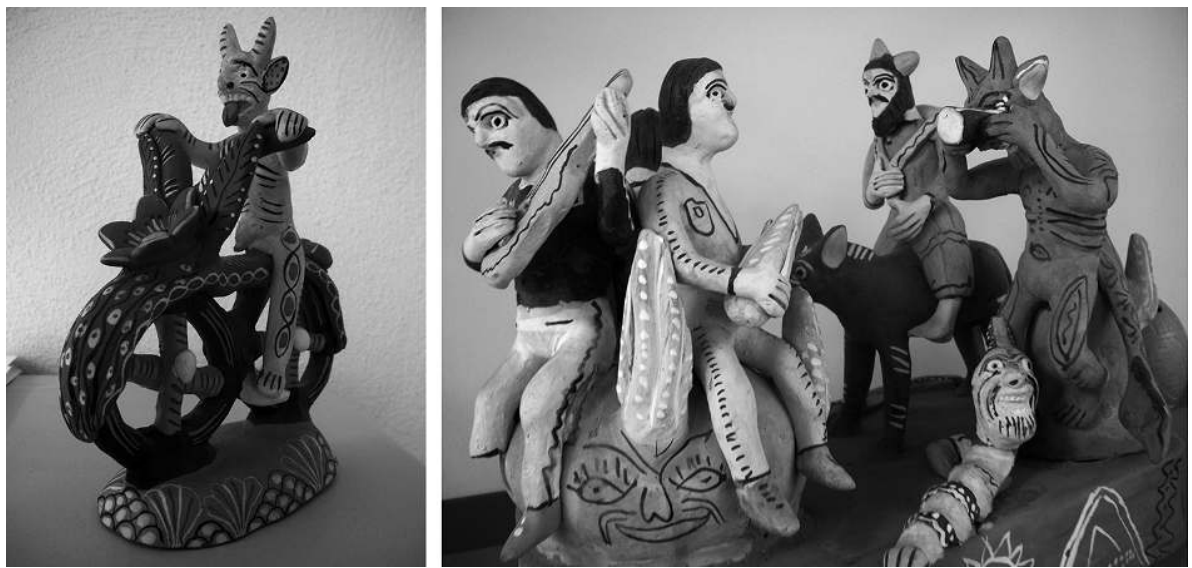

FIG. 4 - El diablo según las figurillas de barro de Ocumicho (2011; foto Araiza). 
Para facilitar el análisis, plantearé que tras la variedad de casos particulares, este evento se conforma de tres secuencias (Figura 5): el «coloquio » de los luzbeles; la adoración del Niño Dios (a cargo de una serie de personajes: pastores, rancheritos, viejitos ${ }^{3}$, ermitaños) y la aparición de decenas, incluso cientos de, por así decir, diablos menores. En la región lacustre las tres secuencias se presentan el mismo día y pueden durar en total unas cuantas horas; en éstas no aparecen los rancheros, sino unos pastores que no dialogan entre sí, sólo danzan.

Así, los diablos adquieren dos formas muy distintas: se presentan primero como luzbeles (Luzbel, Astucia, Pecado y, en algunos casos también, Avaricia, Envidia, Osmodeo y Satán; incluso llegan a ser hasta nueve) al inicio de la pastorela; luego aparecen bajo una variedad de disfraces para marcar el final de la misma. Los luzbeles son por lo general interpretados por varones ${ }^{4}$ solteros de entre quince y veinte años. No está permitido que alguien encarne este papel más de una vez, salvo aquellos que lograron cautivar fuertemente al público con su actuación.

En algunas pastorelas los ermitaños manifiestan expresiones similares a las de los diablos secundarios: provocan al público con gestos grotescos, por lo que, en vez de respeto, inspiran burlas. Así, parece que se disfrazan de diablo, tal como sucedía en ciertas obras del teatro de evangelización del siglo XVI ${ }^{5}$. En otras, cumplen el mismo papel que los pastores, pues impiden que el Niño Dios caiga en las tentaciones a que le incita el diablo, dan consejos sobre el buen comportamiento social, ayudan a que reine la paz en el mundo. Además, vigilan que haya orden durante la representación, dando latigazos a quienes no respetan los límites del espacio teatral. Los ermitaños son interpretados por adultos que han demostrado tener buenos comportamientos sociales y pensamientos sanos, mientras que los que provocan desorden pueden ser interpretados por muchachos, adultos e incluso por niños. Remito al lector a una publicación (Araiza 2013) donde proporcioné más detalles acerca de los otros personajes, sus actos y sus atuendos característicos.

Mediante la distinción analítica en tres secuencias resalta que el evento bajo estudio involucra acciones que corresponden a la pastorela teatral pero también a la tradicional. Hay secuencias que cumplen una función de rito iniciático: la de los rancheros, cuya actuación implica establecer un compromiso de matrimonio; la de los diablos principales es un modo de acceder a cargos civiles o religiosos y la de los diablos menores es, como veremos, una manera de iniciarse al control de las emociones. Bajo estas premisas plantearemos la siguiente hipótesis: la pastorela purépecha involucra ritual y al mismo tiempo teatro, o, para decirlo con Schechner (2000, pp. 21-64), « eficacia » y « entretenimiento », lo cual no implica, como sugiere este autor, que primero se produzca uno y luego - por una transformación, desplazamiento o cambio de perspectiva - el otro: « del ritual al teatro » o viceversa. En la historia del teatro, dice este autor, uno y otro 


\begin{tabular}{|c|c|c|c|c|}
\hline $\begin{array}{c}\text { Secuencias de la } \\
\text { pastorela/aspectos } \\
\text { sobresalientes }\end{array}$ & $\begin{array}{c}\text { Concilio } \\
\text { o coloquio } \\
\text { de los luzbeles }\end{array}$ & $\begin{array}{l}\text { Adoración al } \\
\text { Niño Dios }\end{array}$ & $\begin{array}{c}\text { Adoración al } \\
\text { Niño Dios } \\
\text { (pastorelas de la } \\
\text { Sierra y la } \\
\text { Cañada) } \\
\end{array}$ & $\begin{array}{l}\text { Aparición masiva } \\
\text { de los diablos }\end{array}$ \\
\hline $\begin{array}{l}\text { Tiempo } \\
\text { en el que se sitúa la } \\
\text { acción }\end{array}$ & $\begin{array}{l}\text { Mítico: el de la } \\
\text { divinidad; el del } \\
\text { origen del mal o de } \\
\text { lo no-bueno } \\
\text { Bíblico: la época en } \\
\text { que nació } \\
\text { Jesucristo }\end{array}$ & $\begin{array}{l}\text { Mítico: el de la } \\
\text { divinidad; el del } \\
\text { origen del bien o } \\
\text { de lo bueno } \\
\text { Bíblico: la época } \\
\text { en que nació } \\
\text { Jesucristo }\end{array}$ & $\begin{array}{l}\text { El pasado histó- } \\
\text { rico: la época de la } \\
\text { colonización y a la } \\
\text { vez el presente, el } \\
\text { tiempo de la vida } \\
\text { diaria }\end{array}$ & $\begin{array}{l}\text { El presente y a la } \\
\text { vez el del origen del } \\
\text { mal o lo no-bueno }\end{array}$ \\
\hline Personajes & $\begin{array}{l}\text { Diablos principales: } \\
\text { Luzbel, Astucia y } \\
\text { Pecado (en algunas } \\
\text { versiones también } \\
\text { Avaricia, Envidia, } \\
\text { Ósmodeo y Satán). } \\
\text { Ángeles: Miguel, } \\
\text { Rafael y Gabriel. } \\
\text { Ermitaños }\end{array}$ & \begin{tabular}{|l|} 
Pastores \\
Pastoras \\
Viejitos \\
Ermitaños
\end{tabular} & $\begin{array}{l}\text { Rancheros } \\
\text { Rancheras }\end{array}$ & $\begin{array}{l}\text { Diablos menores o } \\
\text { secundarios: } \\
\text { " negros » } \\
\text { " changos ", } \\
\text { " chalis ", } \\
\text { " ermitaños" }\end{array}$ \\
\hline $\begin{array}{l}\text { Libreto } \\
\text { diálogos que } \\
\text { profieren los } \\
\text { personajes }\end{array}$ & $\begin{array}{l}\text { Invariante } \\
\text { (recitación en verso) }\end{array}$ & $\begin{array}{l}\text { Invariante } \\
\text { (cantos, } \\
\text { villancicos) }\end{array}$ & $\begin{array}{l}\text { Variante } \\
\text { (recitación en } \\
\text { verso) }\end{array}$ & $\begin{array}{l}\text { Variante } \\
\text { (lenguaje } \\
\text { no-verbal } \\
\text { y/o frases breves) } \\
\end{array}$ \\
\hline Tipo de acciones & $\begin{array}{l}\text { Remitir a la primera } \\
\text { lucha entre el bien y } \\
\text { el mal o lo bueno y } \\
\text { lo no-bueno }\end{array}$ & $\begin{array}{l}\text { Adorar al Niño } \\
\text { Dios }\end{array}$ & $\begin{array}{l}\text { Adorar al Niño } \\
\text { Dios }\end{array}$ & \begin{tabular}{|l|} 
Figurar \\
lo no-bueno, \\
crear desorden, \\
« divertirse » \\
\end{tabular} \\
\hline $\begin{array}{l}\text { Valores } \\
\text { fundamentales }\end{array}$ & $\begin{array}{l}\text { Espirituales y } \\
\text { metafísicos }\end{array}$ & $\begin{array}{l}\text { Espirituales y } \\
\text { metafísicos }\end{array}$ & $\begin{array}{l}\text { Materiales, } \\
\text { terrenales, riqueza } \\
\text { material, } \\
\text { comportamientos } \\
\text { sociales acepta- } \\
\text { bles e inaceptables } \\
\text { en esta sociedad }\end{array}$ & $\begin{array}{l}\text { Comportamientos } \\
\text { sociales aceptables } \\
\text { e inaceptables en } \\
\text { esta sociedad, } \\
\text { cuestionamiento al } \\
\text { dominio de lo polí- } \\
\text { tico, económico e } \\
\text { institucional }\end{array}$ \\
\hline $\begin{array}{l}\text { Registro de la } \\
\text { expresión corporal } \\
\text { y narrativa }\end{array}$ & $\begin{array}{l}\text { Sumamente serio e } \\
\text { incluso terrorífico }\end{array}$ & Serio & Cómico & $\begin{array}{l}\text { Cómico, } \\
\text { sarcástico, irónico }\end{array}$ \\
\hline
\end{tabular}

FIG. 5 - Secuencias de las pastorelas de la región purépecha. Fuente: elaboración propia a partir de los diarios de campo de diciembre de 2007 a 2012.

interactúan continuamente, pero luego agrega que cuando uno asciende el otro desciende (ibid., p. 38). En el caso que aquí estudiamos, ambos se producen ante la mirada del público, en el curso mismo de una serie de performances que conforman una unidad: la pastorela. En conjunto, este evento se desarrolla como un mosaico, una forma híbrida que incluye una variedad de diferentes modalidades de actuación. Entonces, cabe preguntarse: ¿Ante qué tipo de evento nos encontramos? ¿Cómo analizar este mosaico sin aislar uno de los componentes (ritual, ceremonia, teatro, fiesta) considerándolo como susceptible de ser estudiado por sí mismo o como una parte que explicaría el todo? 


\section{EL PROCEDIMIENTO DE INVESTIGACION}

Para responder a estas interrogantes, el marco etnográfico se orienta hacia dos direcciones. La primera consiste en centrar la atención en la lógica interna del evento, observando lo que se hace y lo que se dice en el curso del mismo; es decir, « explicar el ritual en sí mismo y por sí mismo » (Houseman 2012, p. 13). La segunda consiste en tomar como base un caso - el de Comachuén - para establecer un contraste con las pastorelas observadas en otras localidades. Así, hemos logrado diseñar un modelo abstracto de la cronología de los eventos que preceden y que siguen al evento llamado pastorela (Figura 4) y de las secuencias de la pastorela (Figura 6).

Si bien la pastorela forma parte del evento festivo más importante del ciclo anual dedicado al Niño Dios, no obstante debemos considerar que a este santo se le rinde culto a lo largo del año por medio de diferentes fiestas, rituales, danzas, etc. (Figura 6). Por consiguiente, resulta indispensable no enfocarse en un solo evento y pretender estudiarlo como si fuera un hecho aislado, sino tener en cuenta « la linealidad de los rituales » (Monod Becquelin y Breton 2002, p. 26).

Ahora bien, si la pastorela se desarrolla como un continuum entre diferentes modalidades de actuación y dado que ésta se encadena con otros eventos a lo largo del ciclo anual, ¿cómo determinar cuál es el inicio y cual el final de una pastorela? Ante esta dificultad, a la que también se enfrentaron Monod Becquelin y Breton (ibid.) en lo que concierne al carnaval de los tzeltales de Chiapas, una respuesta puede ser que el evento inicia cuando termina el precedente. La metáfora de ondas y nudos resulta de gran utilidad para nuestro propósito: los nudos " entre los cuales se encuentran los vientres como etapas en las que conceptualmente se forma el mundo a venir a partir de los elementos precedentes » (ibid.) serían, en el caso de la pastorela el Año Nuevo, el Día del niño, el festejo a la Virgen de Guadalupe y la Navidad (Figura 6).

\section{RituAl Y TEATRO EN ANTROPOLOGía}

Si bien este tipo de eventos, que implica diferentes modalidades de actuación, ha despertado mucho interés entre antropólogos, sociólogos, folkloristas y demás eruditos, sus análisis revelan una tendencia a considerar que todos son de carácter ritual. Además, como demostraron ya varios autores (Houseman y Severi 1994; Díaz Cruz 1998; Lassègue 2003), desde la antropología clásica ha predominado un enfoque que privilegia ciertas dimensiones del ritual - significados ocultos, función social, efectos económicos, políticos - en detrimento de otras - estéticas, artísticas, sensoriales. En México también ha prevalecido esta tendencia y, sobre todo, en la antropología que se aplica a los grupos indígenas (Oseguera 2008; Díaz Cruz 2004). No es de sorprender, ya que con el afán de 


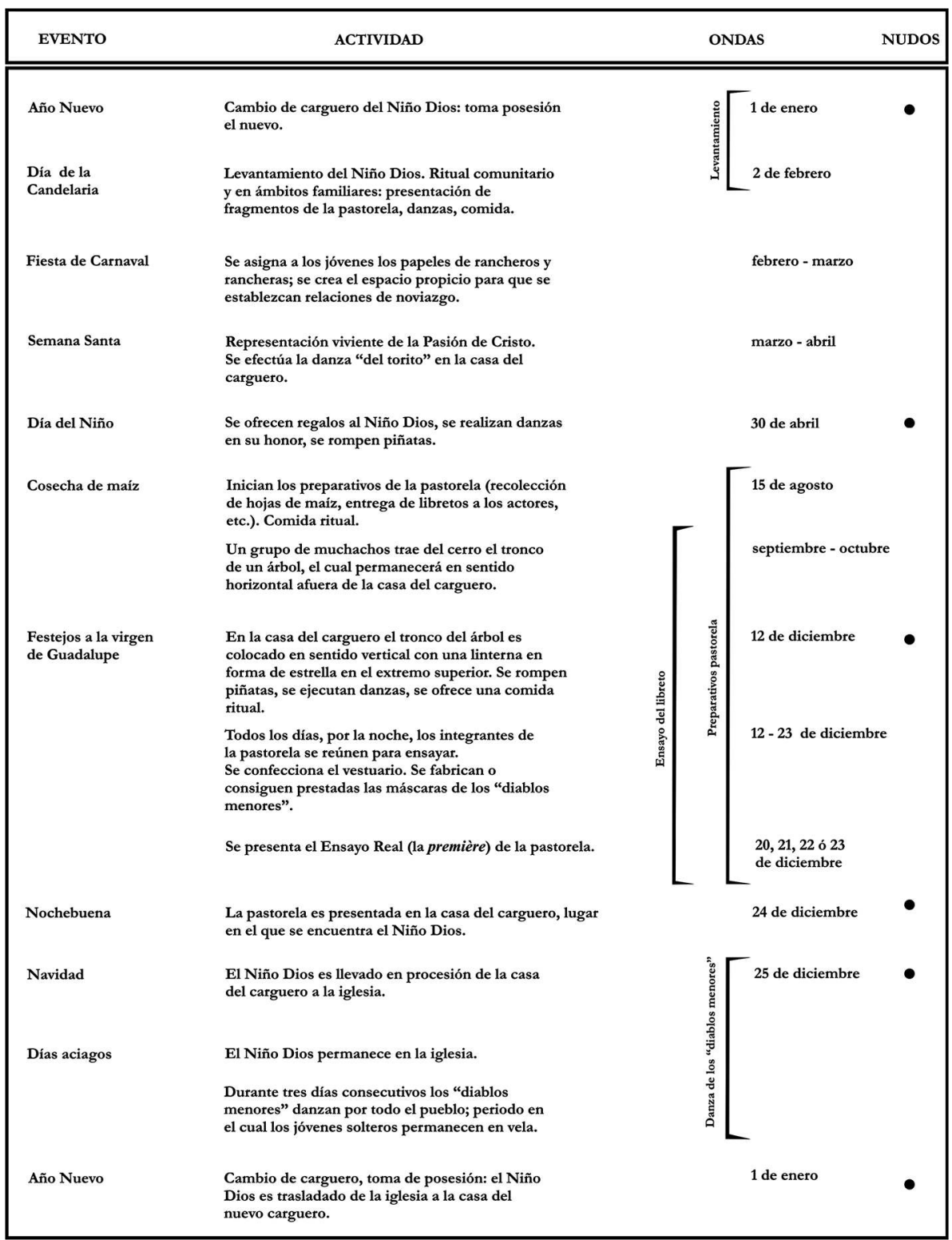

FIG. 6 - Fases que preceden y que siguen a la pastorela. Fuente: elaboración propia a partir de los diarios de campo de diciembre de 2007 a 2012. 
los antropólogos de dar cuenta de la cultura - o la organización social, la cosmovisión, la identidad, la tradición, etc. - entendida como un todo coherente y ya acabado, se ha visto al ritual como un atajo precioso, una vía directa para acceder al conocimiento de ese todo. Es por eso que se ha descuidado el estudio de las propiedades internas del ritual. Y cuando se presta atención a las acciones, se excluyen aquellas de tipo teatral o bien se les engloba a todas bajo el término ritual.

Herskovits (1976 [1948)]) fue uno de los primeros antropólogos en llamar la atención sobre la existencia de « dramas seculares »- o teatro - en las sociedades tradicionales. Observó que estos últimos, comparados con los dramas religiosos, parecen minoritarios o de menor importancia ya que adoptan formas más humildes: « hay en ellos menos pompa y son realizados por grupos más pequeños » (ibid., p. 470). Lo anterior explica, en parte, que los dramas seculares hayan sido excluidos del enfoque antropológico. En el caso de la antropología mexicana, habría que agregar la influencia decisiva que ha ejercido una concepción según la cual los rituales son una puesta en escena de significados ocultos, receptáculos de símbolos preexistentes sobre los cuales los nativos no tienen conciencia y, por tanto, corresponde solamente al investigador el trabajo de descifrarlos ( $c f$. Oseguera 2008; Díaz Cruz 2004). Esta concepción permea particularmente a los estudios que ponen énfasis en lo prehispánico en detrimento de lo católico y establecen como campo privilegiado el sincretismo según los ejes siguientes: orden/desorden, pagano/profano, entre otros. También caracteriza a los que se centran en la función social de los rituales contemporáneos, colocando al sistema de cargos como objeto privilegiado (Korsbaek 1996; Topete Lara 2005) ${ }^{6}$. De ahí que se excluyeran aquellas actuaciones que en apariencia no producen efectos en la vida cotidiana y revelan su proveniencia del catolicismo. En efecto, « las congregaciones pueden salir del ritual con sus estatus, de algún modo formalmente transformados. Las obras de teatro nunca transforman el estatus de los miembros del público, aunque quizá los conmuevan profundamente » (Rappaport 2001, p. 77). Sin embargo, mis datos etnográficos revelan lo contrario; muchas de las actuaciones implicadas en las pastorelas, de las que podríamos decir que " están sólo actuando », es decir " imitando una acción », tienen efectos en la vida ordinaria. Para mencionar solamente un ejemplo, los « rancheritos » que se supone sólo están interpretando a un matrimonio, la gran mayoría - si no es que todos - terminan casados efectivamente en la vida real con su respectivas parejas « ficticias », las rancheras. Podríamos resolver el asunto planteando que esta acción de los « rancheritos », así como la de los otros participantes en la pastorela, son todas de tipo ritual. Pero, quedaría en el aire la cuestión que Herskovits (1976 [1948], p. 470) ya había planteado: "¿cómo clasificar una determinada representación?». En otras palabras: ¿cómo saber ante qué tipo de actuación nos encontramos? Este autor hizo una recomendación desde aquel entonces: " no considerar que todas son de tipo ritual » (ibid.). Al parecer, pocos autores hicieron caso de ella. 
En los últimos años, las ciencias sociales y humanas experimentan un giro performativo y con ello un desplazamiento del ritual a la performance. No obstante, pareciera que simplemente se ha sustituido un término por otro. La performance es vista ahora como un valioso atajo para acceder al conocimiento de un dominio más amplio llamado cultura. Así, el término performance se comenzó a aplicar a casi todo tipo de actuación. Es por eso que Goody cuestiona la tendencia actual que busca coincidir con Schechner y con Turner ${ }^{7}$, y consiste en « borrar cualquier diferencia entre teatro y ritual bajo el término indefinido de "representación" (performance) »(Goody 2001, p. 147). A contra corriente, algunos autores (Herskovits 1976 [1948]; Rappaport 2001; Goody 2001; Houseman 2003) plantean que es necesario establecer criterios para distinguir unas actuaciones de otras, dado que, aunque tengan un " aire de familia », no todas son de la misma naturaleza. Uno de estos criterios es el texto. La ausencia de éste caracterizaría al ritual, mientras que el « argumento » o el « guión » - un conjunto de indicaciones transmitidas de manera oral para orientar la acción corporal (Schechner 2003 [1988], pp. 66-169) - definiría al teatro de las sociedades tradicionales. Otro criterio es la separación entre actores y espectadores, que sería propia del teatro, en tanto que la unión de éstos sería un rasgo distintivo del ritual. En el teatro los papeles de los actores y los del público estarían claramente diferenciados, mientras que en el ritual podrían intercambiarse en determinados momentos. Más importante aún, quienes asisten al ritual constituyen una congregación y la participación es un elemento clave que define el papel de cada uno de los miembros de ésta en el evento (Rappaport 2001, p. 76). Quienes concurren al teatro por lo general no se conocen entre sí. Las personas que asisten a la pastorela constituyen en efecto una congregación, pero por momentos se ponen de manifiesto las cualidades que Rappaport (ibid.) atribuye al teatro: separación y diferenciación de los papeles que corresponden al público y a los intérpretes.

Quizá uno de los criterios a los que más se ha recurrido es la diferencia entre « estar solamente actuando » o « imitar un acto » y realizar una acción « en serio », lo cual no quiere decir que excluya el humor. En esta misma tesitura, se estableció que actuar es del orden de la "representación », que implica hacer presente algo o alguien ausente, mientras que actuar en serio es del orden de la " presentación » que consiste en hacer advenir algo o alguien al momento en que se realiza la acción. Esta última sería propia del ritual mientras que la primera sería propia del teatro (Goody 2001; Marin 1994). En principio, esta distinción se podría aplicar perfectamente al caso de la pastorela: los luzbeles no son una representación del diablo, sino una manera de crear la presencia de éste. Los actos que ellos realizan son del orden de la « presentación », una aparición o algo como una hierofanía. Pero no habría justificación para argumentar que los otros personajes no realicen una "presentación" en este sentido, entonces todos realizan acciones de tipo ritual. Si los participantes mismos distinguen entre las 
actuaciones implicadas, otorgándoles nombres diferentes, eso significa que debemos continuar buscando en qué estriba la diferencia. Además, como podremos apreciar en adelante, en la pastorela cada una de estas actuaciones pone en marcha modalidades sensoriales particulares y remite a una variedad de referentes.

\section{EFICACIA Y ENTRETENIMIENTO}

Páginas arriba remitimos a la propuesta de Schechner para sugerir algunas de sus limitaciones, pero es necesario precisar en qué aspectos concretamente se revela poco conveniente para nuestro objeto de estudio. Para hacer justicia a este autor, comenzaremos reconociendo hasta qué punto, pese a su borrosidad, el concepto de performance, ha contribuido a explorar nuevas pistas de indagación. Una de estas consiste precisamente en salir de los debates que oponen ritual y teatro. Habría que considerar, anota Schechner (2000, p. 36), que la polaridad en realidad no se da entre éstos últimos sino entre eficacia y entretenimiento. Así, construye un esquema encabezado, por un lado, con el «rótulo » eficacia y, por otro, con el de "entretenimiento », seguidos de ritual y teatro a los cuales corresponden respectivamente las siguientes cualidades: un Otro trascendente/sólo para los presentes; tiempo simbólico/énfasis en el ahora; actor poseído o en trance/actor que sabe lo que hace; el público participa/el público mira; el público cree/el público aprecia; no se invita a la crítica/prospera la crítica; creatividad colectiva/creatividad individual (ibid.).

Intentemos ahora aplicar este esquema al caso de la pastorela. En efecto, la pastorela se realiza cada año y las personas participan motivadas por el fuerte deseo de pagar una manda al Niño Dios (un otro trascendente). A cambio de ciertos favores que éste les concede: sanar una enfermedad, interceder ante una dificultad en el trabajo, en los estudios, etc. se le ofrece una pastorela. La manda consiste en interpretar uno de los papeles. Pero no basta con participar. Hay que hacerlo bien. Hay que actuar cada uno de los papeles correctamente, con mucho esmero y dedicación. Sin embargo, los actores no están en estado de « posesión o de transe ». Algunos pueden haber ingerido alcohol sin que esto implique una alteración de su conciencia. Ellos sí « saben lo que hacen ». Así se espera obtener resultados de diversa índole: que el Niño Dios esté contento; que los organizadores y los actores logren ascender en el estatus social, etc. Por ejemplo, un buen intérprete - sobre todo del papel de diablo - o un buen maestro de pastorela pueden llegar adquirir mucho prestigio y autoridad y ocupar cargos importantes en el sistema de organización social.

La pastorela también se dirige a los presentes y el público participa. Pero, sí prospera la crítica. En efecto, todas las actuaciones de la pastorela son constantemente evaluadas por un grupo de notables: autoridades civiles y religiosas, consejo de ancianos. Estos determinan si un papel, canto, paso de 
danza o pieza musical, ha sido bien interpretado o no, si un vestuario, máscara o escenario quedó bien elaborado o no. En realidad, si bien todos los integrantes del pueblo contribuyen de algún modo para que la fiesta se lleve a cabo, la realización de la pastorela es responsabilidad directa de dos personas: el encargado del Niño Dios y el maestro de pastorela. Este último funge como un director de escena, se encarga de dirigir los ensayos y dar indicaciones precisas sobre el estilo de la actuación: la gestualidad, el tono de voz, la entonación al proferir las frases plasmadas en el texto, etc. (creación individual). Además guarda celosamente un repertorio de obras, muchas de las cuales, según se afirma, son muy antiguas ${ }^{8}$. A cambio de este trabajo, los maestros de pastorela reciben una remuneración económica por parte del carguero en turno o de la colectividad. Algunos dicen que no lo hacen por dinero sino para pagar una manda al Niño Dios o por compromiso hacia la colectividad. Si la pastorela resulta mal realizada la responsabilidad recae primero sobre el maestro de pastorela y luego sobre el encargado del Niño Dios. Pese a que algunos libretos han sido escritos por autores anónimos, es el maestro de pastorela quien los interpreta (creación individual). También, se reconoce en los pueblos purépecha a quienes son autores de los diálogos de los rancheros, así como de las piezas musicales y de los cantos que forman parte de la pastorela.

Por último, la pastorela tanto remite a un tiempo simbólico, como hace énfasis en el ahora. Podemos mencionar algunos elementos de la pastorela que la acerca al teatro: el libreto, al cual ya hice referencia, y el escenario. Este último debe ser nuevo cada año y puede consistir en un sencillo tablado o en una construcción muy grande y sofisticada. Los materiales que se utilizan para ello son proporcionados por un grupo de muchachos solteros. Éstos deben adentrarse en el monte para buscar un enorme tronco de pino, al cual se coloca, a modo de señal, con una estrella de plástico rojo, en la casa del carguero (Figura 2, arriba derecha). También deben recolectarse hojas de nuriten ${ }^{9}$ y flor de melón (musgo) y cortarse varios troncos de árbol, que servirán ya sea para dar forma al sencillo tablado o bien al sensacional palacio. Estas acciones revisten un carácter ritual, son un rito iniciático.

Por consiguiente, solamente forzando mucho se podría hacer entrar a la pastorela purépecha en uno de los polos antes mencionados. Es por eso que debemos recurrir a otras propuestas. Al respecto, Houseman (2003, 2008, 2012), desarrolló un esquema centrado en la acción, evitando así empantanarse de entrada con el espinoso asunto de la creencia. ¿Cómo podríamos saber y comprobar lo que el público y los actores creen? Así, proporciona una serie de indicaciones para orientar el análisis de fenómenos que podrán ser considerados como acciones ordinarias, juego ritual o teatro poniendo en relación la experiencia de los participantes en una pluralidad de modos de interacción diferentes (Houseman 2003). 


\section{Música Y SONIDOS}

En lo que sigue intentaremos hacer una aproximación a la experiencia de los participantes en la pastorela y a las diferentes modalidades de interacción que ésta pone en marcha. Trataremos de demostrar que no solamente es la acción y la palabra lo que proporciona a los participantes un marco para que ellos elaboren su propia experiencia, sus propios estados afectivos e intencionales, sino que juegan un papel relevante al respecto las modalidades sonoras, musicales, gestuales. La adhesión de los participantes a las realidades que se ponen en escena (eficacia) depende en gran medida de estas modalidades. Para ello analizaremos las modalidades musicales y sonoras, la gestualidad y los tipos de interacción; finalizaremos explorando un tipo de experiencia: la de los diablos secundarios, en la que precisamente son las acciones las que preparan a los participantes para que experimenten una sensación de poderosa energía. Comencemos pues identificando las modalidades sonoras y musicales.

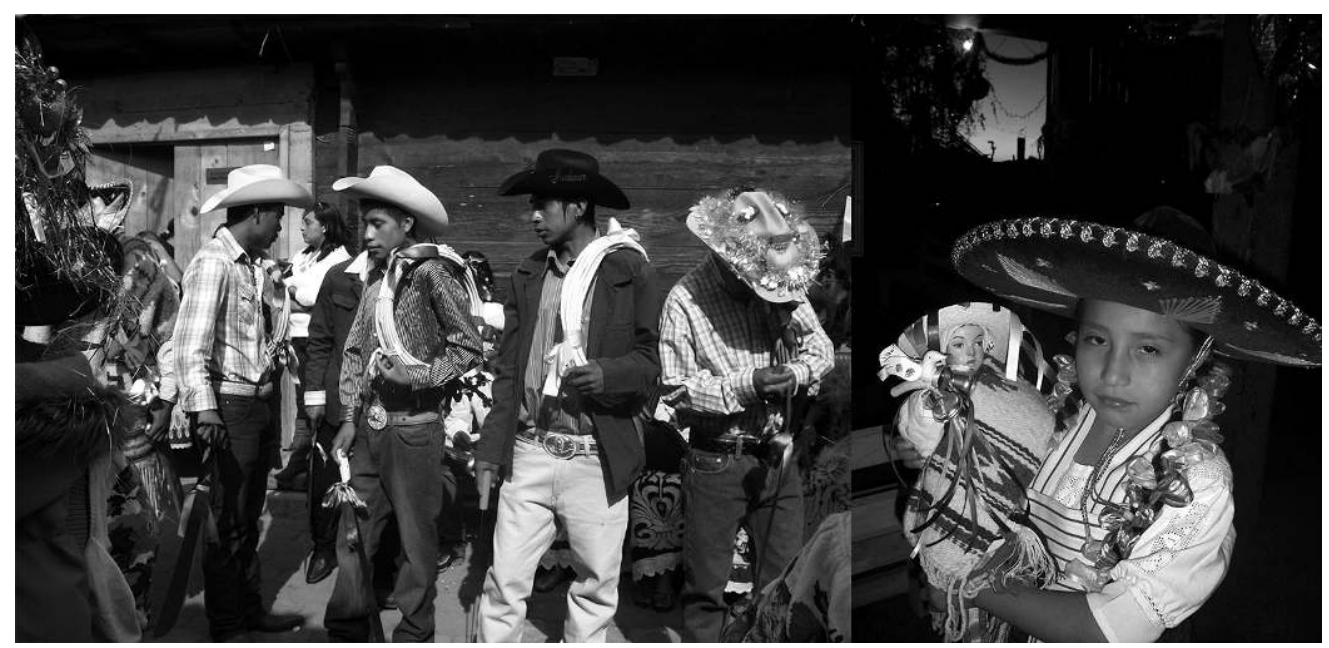

FIG. 7 - Rancheros preparándose para actuar en la pastorela de Comachuén (2010 y 2011; fotos Araiza).

La música, como la danza, juega un papel fundamental en la pastorela. Cada personaje se caracteriza por una tonada particular y distintiva: polkas y abajeños ${ }^{10}$ para los luzbeles, sones para los pastores y los rancheros (Figura 7). Los músicos trabajan en estrecha colaboración con los maestros de pastorela. Tienen que componer una tonada diferente cada año y para cada personaje, o bien hacer arreglos a las tonadas del repertorio que ya se tiene (el cual se dice que es muy 
antiguo). En Comachuén, por ejemplo, quienes van a interpretar el papel de rancheros, buscan al músico y le presentan ciertas letras antiguas que han recuperado de sus abuelas o bisabuelas y entonces el músico les hace arreglos. $\mathrm{O}$ bien llevan una tonada antigua y le piden al músico que adapte la letra. Así, éste llega a componer cada año cerca de veinte partituras. De modo que además del archivo de libretos se tiene otro de tonadas musicales. Esta exigencia - a saber que la música de pastorela sea de reciente creación - es compartida por otros poblados de la Cañada y de la Sierra. Como demostró Chamorro (1994, p. 134), la clasificación habitual del son presenta en estas regiones una gama muy amplia dentro de la cual el « son de estreno » corresponde precisamente al que se toca en las pastorelas. En Ichán y en Quinceo, por ejemplo, la orquesta que acompaña el baile de la ranchera y el ranchero, tiene que comprometerse a tocar solamente sones inéditos: ninguno « que se haya oído antes » (ibid.).

El ritmo sirve como indicador de las sensaciones experimentadas por los personajes. Una cadencia lenta indica el cansancio de los cuerpos después de una larga caminata. Una tonada «profundamente melancólica y lánguida » a la que se denomina « letra » sirve para introducir el dialogo de Luzbel. Enfatiza la profunda carga sentimental de las lamentaciones de este personaje. Otra melodía, llamada "media letra », "permite que el intérprete respire para continuar con su diálogo » (Márquez 2005, p. 14). En todo momento hay musicalidad - en los versos que recitan los personajes y de modo particular en los parlamentos de los diablos principales - y los sonidos son relevantes. En cuanto a los sonidos producidos por la entonación y la elocución de los actores, justamente, para interpretar a Luzbel hay que tener un atributo particular: un cierto tono de voz, un estilo de elocución con determinado ritmo. Según explica don Patiapa Vargas (quien durante más de diez años interpretó a Luzbel), no basta con haber memorizado las palabras que están en el libreto: «tienes que recitar bien, como si se alargaran las palabras, como arrastrando más las palabras » (cuaderno de campo, 15 de agosto de 2008). Estos universos sonoros y musicales cobran sentido acorde a las ejecuciones corporales y verbales de los diablos principales.

De este modo, los purépecha han desarrollado una habilidad particularmente aguda para identificar una buena polka, un buen son o un buen canto del que no lo es. Sin embargo, corresponde a un grupo de notables conformado por ancianos, autoridades religiosas y civiles, principalmente el tata juramuti- jefe de tenencia -, evaluar la correcta ejecución musical, así como valorar la actuación y la correcta interpretación de todos los personajes, especialmente la de los diablos principales. Nuestra reflexión acerca de cómo se imbrican diferentes modalidades de actuación se ve así enriquecida. Podemos notar cómo, pese a la importancia que se le otorga al texto escrito, no es éste el que impera, sino la creación de diferentes universos sensoriales, entre los cuales la música y el sonido. Éstos a su vez no están ahí sólo para crear un cierto ambiente, no 
son mero acompañamiento o el intermedio entre una escena y otra, más bien son componentes fundamentales de la performance. Es como si el texto escrito se adaptara al cuerpo del intérprete y no a la inversa como en la mayoría de producciones teatrales. Cabe abundar aún sobre las diferentes modalidades sensoriales implicadas en la pastorela.

\section{JUEGO ENTRE GESTUALIDAD Y TEXTO}

Los luzbeles se desplazan en línea recta dando unos pasos cortos hacia delante, luego giran y vuelven sobre sus pasos. Este desplazamiento se repite incesantemente: van y vienen mientras discurren sobre las grandes interrogantes de la humanidad (véase infra). Para enfatizar el tono emocional de una frase o la máxima tensión de una situación, sacuden de manera exagerada la cabeza o extienden sus brazos hacia arriba o a un costado. Si bien no es ésta una actuación de tipo naturalista - por ejemplo al decir « voy a ti corriendo a paso veloz », no corren de verdad - tampoco evoca una acto dancístico, ya que su modo de caminar es a paso normal, sin golpear el suelo con los zapatos de manera rítmica. Definitivamente, lo que provoca en el público esa actitud - entre el temor y atracción - no es tanto la gestualidad de los luzbeles sino la sonoridad que son capaces de crear: el tono de su voz y el ritmo de su entonación al proferir los enunciados.

En contraste, las secuencias correspondientes a los rancheros, por un lado, y a los cientos de diablos, por otro, presentan cambios tanto formales como de contenido. Admiten un grado mayor de improvisación, recreación e invención, solicitando la colaboración de otros dramaturgos y poetas locales. En estas dos secuencias ya no se trata de escenificar un pasaje de los evangelios, sino acontecimientos vividos realmente ${ }^{11}$.

Si los diálogos de los rancheros presentan variaciones, en cambio su actuación parece regirse cada vez por un mismo esquema coreográfico: bailan un zapateado; se desplazan en línea recta dando pasos de forma natural; giran y vuelven sobre sus pasos; cantan una canción de cuna; se detienen de frente al público, mencionan sus respectivos nombres y apellidos, dialogan entre sí haciendo alarde de riqueza material (las extensiones de tierra y el ganado que poseen, la vida de lujos que llevan). También hacen referencia a problemas que se viven en la comunidad, en el país o en el mundo. Si bien hay una parte de improvisación, los actos de estos personajes no son en definitiva una adaptación teatral del texto escrito. En este aspecto se asemejan más a las acciones rituales: «formas de conducta bien definidas, convencionales o estipuladas, "actos arquetípicos" a los cuales las condiciones ordinarias de intencionalidad no podrían aplicarse » (Houseman 2003, p. 296).

En contraste, la actuación de los diablos menores varía tanto en la expresión verbal como en la ejecución corporal. Ésta no se rige por un esquema 
coreográfico previo. Recordemos que el escenario que ocupan no es ya un espacio delimitado como tal, sino las calles, la plaza central, la casa del carguero, el pueblo todo. En lugar de palabras emiten sonidos guturales que semejan bramidos, aullidos o ruidos de animales. Así, en algunas pastorelas de la región lacustre, los diablos menores llevan un atuendo - vestuario, máscara, objetos escénicos - en el que se reconoce claramente a ciertos políticos, actores de televisión, personas destacadas a nivel regional, nacional e incluso mundial. Estos diablos realizan pasos acelerados, ademanes grotescos, gestos enfáticos, profiriendo frases breves y claramente improvisadas, las cuales remiten a algunos de los problemas, conflictos o situaciones de actualidad (elecciones para el gobierno municipal, estatal o nacional, prácticas de corrupción y clientelismo, el maltrato a los pacientes en los hospitales, etc.). Entre tantos diablos menores distinguimos claramente, por su vestuario y su máscara, a unos militares, tal vez sean miembros del ejército, y también vemos delincuentes y narcotraficantes. No deja de llamar la atención que, a diferencia de los otros personajes, éstos sean representados privilegiadamente bajo el registro de la pura gestualidad, prescindiendo de inscripciones (frases escritas en hojas de papel) y expresiones verbales. Se les distingue por sus vestuarios y sus armas (de utilería), que por momento usan apuntando contra el público o bien enfrentándose unos a otros, o simplemente deambulando por el escenario, asechando. En esta modalidad de representación se pasa por silencio todo aquello que concierne al ejército y al narcotráfico, pero no se oculta, se muestra, se hace visible.

\section{DifERENTES TIPOS DE INTERACCIÓN}

La pastorela se desarrolla al modo de una ondulación entre momentos de máxima tensión que provocan en el público actitudes de seriedad, asombro, incluso temor, y momentos sumamente lúdicos, que lo incitan a la broma y al comentario chusco, silbidos y gritos de complicidad. Así, no obstante la tensión máxima que se produce en el curso de la actuación de los luzbeles, pese a la fascinación que su apariencia provoca, la barrera entre éstos y la audiencia es infranqueable. Del lado del público todo es silencio y en cierto modo inmovilidad. En cambio, tan pronto como aparecen los rancheros, esa barrera imaginaria desaparece. Lo mismo sucede en el curso de la actuación de los diablos menores. En esos momentos lo que impera es una interacción, incluso directa, entre la audiencia y los actores. En este aspecto, las pastorelas de la región purépecha contrastan respecto de las que se realizan en otras regiones, por ejemplo las que documentaron Bauman y Ritch (1994) en una comunidad rural y mestiza del estado de Guanajuato. Estos autores notaron que la presentación principal de la pastorela de Tierra Blanca adquiere un tono de suma seriedad y se caracteriza, al 
parecer, por la ausencia de interacción entre actores y público. No obstante, durante los ensayos - incluido el ensayo real - cualquier palabra o gesto de los actores era motivo para que se desencadenaran una serie de comentarios chuscos, bromas, juegos de palabras o alteraciones en los diálogos para cambiar el sentido. Mantenían estas actitudes no solamente los actores entre sí, sino ellos con las personas que asistían a ver los ensayos.

Ahora bien, en el caso de los purépechas, los ensayos por lo general se desarrollan en un ambiente de suma seriedad. Los maestros de pastorela no permiten que los actores se distraigan. Los intentos, ya no digamos de hacer bromas, sino siquiera cualquier tipo de comentario o ruido son reprendidos severamente por el maestro. Los actores deben permanecer sentados en silencio esperando su turno para entrar en la acción. Además, por lo general no se permite que la gente asista a ver los ensayos. Nadie, salvo los familiares del carguero del Niño Dios y las muchachas que sirven el atole y los tamales cada noche a los actores, deben verlos mientras se preparan. Para puntualizar: la interacción entre actores y público varía de una secuencia a otra y lo que Schechner llama «entretenimiento»(2000, pp. 35-40) se produce en el curso mismo de la performance, más no durante los ensayos. Por lo general en éstos se evita el entretenimiento y la interacción con el público. De suerte que eficacia y entretenimiento pueden imbricarse en una misma secuencia.

\section{Tener UnA EXPeriencia}

Pareciera que es fácil interpretar el papel de los diablos menores puesto que no tienen un texto, largos parlamentos a memorizar y tampoco una coreografía a seguir. A primera vista, solamente se trata de salir y provocar desorden, efectuar un baile frenético o realizar ciertas acciones para divertirse o " echar relajo » disponiendo de un amplio margen de libre improvisación. No obstante, ¿por qué se dice que su actuación es igual de importante que la de los luzbeles y que de hecho no se establezca distinción entre estos y aquellos? ¿Cómo logran estos diablos menores crear sus papeles para provocar esa fascinación en el público? La exegesis local la atribuye a que son capaces de generar una poderosa «fuerza » 0 « energía ». Claramente esta sensación de fuerza es generada por la presencia masiva de estos personajes. Al ser numerosos y al aparecer por todos lados, dan la impresión de que el diablo está entre nosotros, aquí en este pueblo, en este mundo; más aún: como si todos pudiéramos serlo. Sin embargo, hay algo más, que solamente se puede comprender interrogando a los intérpretes mismos sobre su experiencia. Escuché decir ${ }^{12}$ que este personaje no es anodino y no es para nada fácil interpretarlo. Cuando un diablo sale e interactúa en la calle, la plaza, donde sea, con otros diablos, de pronto siente que debe sacar toda su energía y a la vez resistir a la fuerza que provocan los otros: 
Es como entrar en un espacio y quedar en medio de fuerzas opuestas que te empujan y te obligan a salir de ese espacio y tú debes resistir, no debes permitir que te saquen. Es un gran reto, una prueba de fuerza. Sientes las energías de los otros diablos que tratan de doblegarte, humillarte y tú no debes dejarte impresionar. No se trata de golpes, no necesariamente te pegan o te sacan con fuerza física, sino con la pura presencia.

Algunos atribuyen a la máscara misma, al hecho de que está encantada, esa sensación de energía incontrolable que invade de pronto a quien se la pone. « Desde el momento mismo en que te pones la máscara sientes ya esa fuerza, esa gran energía, te tiembla todo el cuerpo, te dan ganas de saltar, de empujar ».
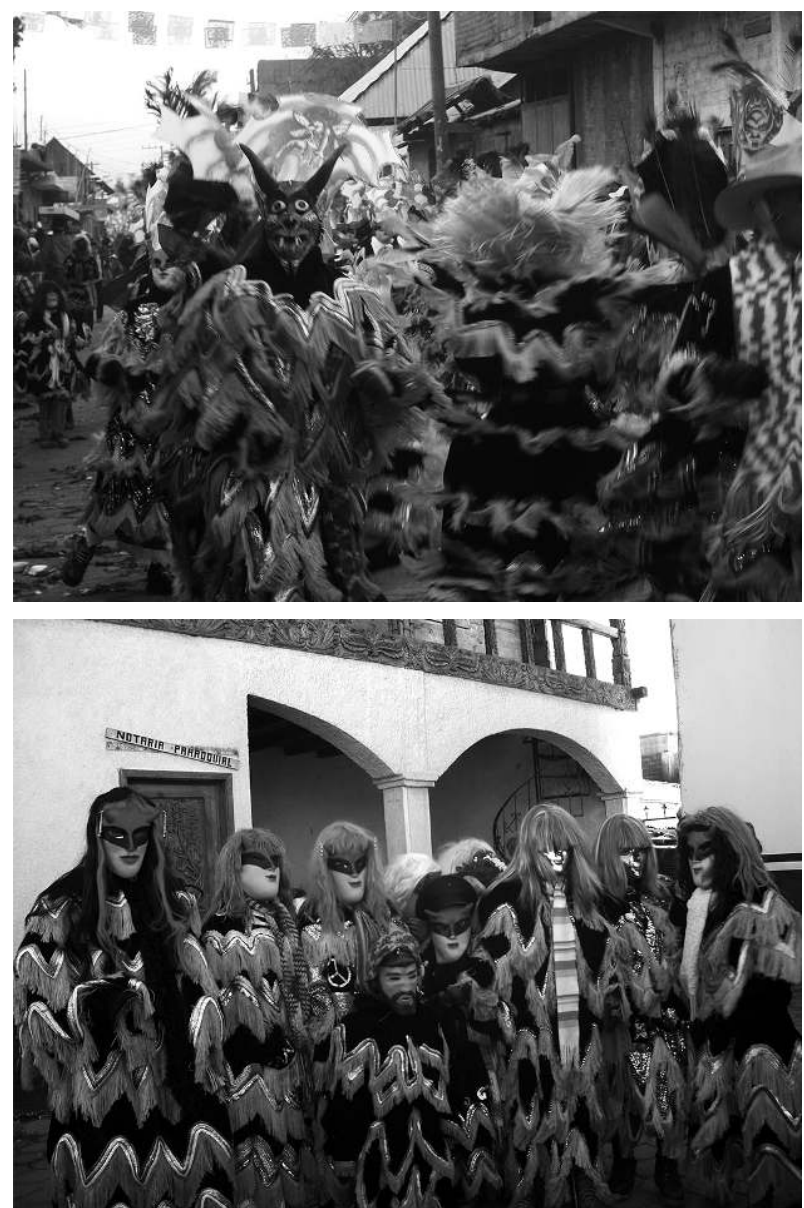

Fig. 8 - Diablos menores durante la tercera secuencia de la pastorela, Comachuen (2011; fotos Araiza). 
Los muchachos forman grupos, llamados « cuadrillas », se juntan según lazos de parentesco, de amistad o por afinidades diversas y usan máscaras y vestuario con formas similares. Así andan por todos lados unidos en grupos de diez o más diablos (Figura 8).

En otros tiempos se enfrentaban uno a uno sin lastimarse, únicamente se retaban con la energía que transmitían. Hoy en día se intimidan de otras maneras. Algunos usan la fuerza física: se empujan, se dan de golpes. Incluso en sus vestuarios llevan ciertos adornos: estoperoles, cadenas, cinturones con formas punzocortantes que pueden quitarse fácilmente para usarlos como armas. También se han dado casos de uso de navajas o cuchillos, al grado de que ya ha habido muertos durante esta secuencia. Al preguntar a qué se debe esto, me comentaron que « a veces es porque ya traen bronca de antes », o bien que « son unos que vienen de otros pueblos ». Así, resulta particularmente esclarecedora la reflexión de Chamorro: « los purépechas son un pueblo altamente sensible a un modo antagónico y emocional de existencia, es decir, una manera de ser en la cual la existencia no tendría sentido sin la presencia de las rivalidades y los sentimientos » (1994, p. 33). Sin embargo, llama la atención que sea precisamente en el curso de la danza de los diablos menores que la rivalidad, la competencia y el sentimiento tan característicos de los purépechas desemboque en expresiones violentas. En otras danzas, incluso en las que se realizan con el mismo propósito de venerar al Niño Dios, por ejemplo, la de los kurpites en San Juan Nuevo, aunque hay provocaciones - gritos de euforia y expresiones de reto que irritan al contrincante -, no se llega al enfrentamiento físico, se evita el paso al acto, la rivalidad expresada a golpes y puñaladas, pues la danza podría ser suspendida (Topete Lara 2011, p. 140). En ambos casos lo que está en juego es la creación de un marco ritual para iniciar a los participantes en el control de las emociones. Se puede apreciar hasta qué punto estas modalidades sensoriales, así como las interacciones y los universos referenciales, se distinguen claramente respecto de los que se ponen en marcha en la actuación de los luzbeles y la de los rancheros.

\section{Ritual Y TAMBIÉN TEATRO}

Estas consideraciones conducen a plantear nuevamente la cuestión del tipo de evento al cual asistimos: ritual o teatro. La propuesta de Houseman (2003, pp. 289-312) señala una vía prometedora para salir del impase. El ritual, señala este autor, es un tipo de acción particular; las acciones del ritual no notifican acerca de cuáles son las intenciones, disposiciones, estados emocionales de las personas involucradas en ellas (ibid., p. 296). En los rituales lo que cuenta es la acción y es ésta la que proporciona a los participantes un marco para que ellos elaboren sus propios estados emocionales, sus intenciones y disposiciones. Si alguien llora o grita en el curso de un ritual, no es porque se sienta realmente triste; es una acción prescrita en el marco mismo del ritual (ibid.). 
Inspirándonos de este planteamiento podemos interpretar que si los diablos menores tienen esa sensación de fuerte presencia o energía poderosa, no es porque realmente crean en el diablo o que ellos lo sean - algunos creerán, otros no, que la máscara, por estar encantada, los hace sentir así -, sino porque es una acción prescrita en el ritual y, al realizarla, ellos elaboran sus propias sensaciones. Asimismo, la secuencia de los rancheros no es simplemente una representación invertida de las relaciones de poder; es algo más complejo: " una puesta en acto inhabitual» (Houseman 2008, pp. 109-114) de dichas relaciones. Los purépecha que se visten y se comportan como rancheros no están expresando una intención de dejar de ser indígenas, sino que están realizando acciones prescritas en el ritual y a partir de las cuales elaboran sus propios estados emocionales respecto de las relaciones conflictivas que en la vida ordinaria ellos mantienen con los rancheros.

Las acciones rituales - anota Houseman (ibid.) - son «polisémicas, ambiguas, incluso paradójicas ». Implican una condensación de modalidades de relación nominalmente antitéticas. Al respecto, cobra particular sentido el diálogo entre el ranchero y la ranchera donde, a cada afirmación de identidad, sigue de inmediato un testimonio de diferencia. Por ejemplo, se presenta a un ranchero que presume tener grandes extensiones de tierra, ganado, mucho dinero, una vida de lujos y viajes y luego la ranchera niega con sarcasmo tal presunción. Un ranchero afirma que es gracias al apoyo del gobierno que obtuvo sus riquezas, mientras que otro atribuye su miseria al mismo gobierno. Las acciones de la pastorela en conjunto revelan el carácter multiplex, que es propio de los rituales, ya que « reúnen en una misma secuencia de acción una pluralidad de elementos preexistentes provenientes de dominios muy diferentes » (Houseman 2008, p. 110). Los lazos de parentesco y de alianza - entre ranchero y ranchera -, las posiciones sociales de prestigio y de autoridad, las rivalidades entre sectores sociales dentro de la comunidad y entre los poblados circunvecinos, todo esto se actúa de manera inhabitual en la pastorela.

En cambio, con el concilio de los luzbeles, asistimos a otro tipo de acciones. Las condiciones pragmáticas que, según el modelo en cuestión, son propias del teatro están reunidas en esta secuencia: un texto a pronunciar, la mirada de los espectadores, las ideas de un director. Quienes ejecutan estas actuaciones se someten a una larga preparación, un aprendizaje técnico, realizan varias sesiones de ensayos, memorizan largos parlamentos para recitarlos, se visten, se colocan máscaras o velos sobre el rostro, para presentar un personaje cuya vida, experiencia, intenciones son separables de las suyas propias. El intérprete de Luzbel actúa en escena como « un sujeto virtualmente desdoblado: actor (singularizado por su propia vivencia afectiva e intencional) y papel (representación distanciada de un modelo de la experiencia) se imponen como distintos pero necesariamente ligados entre sí » (Houseman 2003, p. 297). Sin embargo, pese a que la secuencia de los luzbeles es la más teatral, no admite casi 
improvisación: lo que se recita es lo que aparece en el libreto, el actor obedece en mayor medida a las indicaciones del director y en menor medida a lo que es su propia experiencia. A partir de estas premisas, podemos establecer que las actuaciones de la primera secuencia de la pastorela son de tipo teatral, mientras que las de la segunda y la tercera son de tipo ritual.

\section{Concluyendo Sin Finalizar}

Como hemos visto, en la pastorela se ponen en marcha diferentes tipos de actuación, los cuales a su vez implican una variedad de modalidades sensoriales, interacciones y universos referenciales. En este sentido, el caso purépecha se distingue respecto de otros casos en los que teatro y ritual se imbrican, por ejemplo los fenómenos de transe y/o posesión que implican « aspectos teatrales » (Leiris 1958). En la pastorela, lo teatral no implica que las acciones rituales simplemente hayan sido revestidas con gestos demasiado exagerados o cierta afectación en el comportamiento. Tampoco consiste en que un instante teatral o un « aire lúdico » (Bauman y Ritch 1994), en el sentido de algo cómico o profano, se intercale o irrumpa por momentos en un ámbito regido por la seriedad, lo religioso o lo ritual, lo que corresponde, por ejemplo, al caso de los gags cómicos implicados en el culto en Kerala documentado por Tarabout (1998). En la pastorela, la relación entre ritual y teatro no es evolutiva, no implica el paso de un tipo de actuación que sería más « auténtica » o " primigenia », ligada a lo sagrado, lo comunitario, hacia otra que estaría desprovista de estas cualidades, vuelta espectacular, mera exhibición y simple divertimento para dar gusto a la sed sensacionalista de eventuales turistas. Hay numerosos trabajos que enfocan la transformación de rituales indígenas en teatro, por ejemplo el Rabinal Achí (Henríquez 2008). Si acaso las pastorelas estén sufriendo este tipo de transformación, no podría atribuirse únicamente al turismo, ya que el público de éstas sigue estando conformado en la gran mayoría de los casos por los purépechas mismos. La pastorela, que sigue siendo un evento comunitario, constituye un mosaico en que cada una de las partes - teatro, ritual, performance, juego - actúa de manera muy diferente desde realidades particulares e implicando determinadas relaciones sociales. Lo interesante es que una actuación no predomina sobre la otra. Es como si lo importante fuera poner una actuación al lado de la otra aunque los rancheros, los «narcos" o los políticos del momento no tengan que ver con el pasaje evangélico que se pone en escena. La adhesión de los participantes a las acciones puestas en escena - la eficacia - quizá dependa de esta combinación ya sea equilibrada o llena de tensiones de diferentes tipos de actuación. Dada la complejidad de elementos que entran en juego en las pastorelas y las variantes locales, quedan aún por estudiarse muchos aspectos. Habría que profundizar más aún sobre la variedad 


\section{de realidades particulares que se ponen en escena y que provienen de diferentes dimensiones de la vida ordinaria.*}

* Manuscrit reçu en mai 2013, accepté pour publication en décembre 2013.

\section{Notas}

1. Según éstas, el diablo aparece en el monte, las barrancas, las cuevas, bajo la forma de burro, perro gigantesco, toro o víbora, charro o mujer seductora. Lo ven aquellas personas que no cumplen con las obligaciones religiosas, acaparan riquezas, son infieles o alcohólicos.

2. Entre los purépechas, el diablo está asociado ante todo con la Navidad; en las fiestas de Carnaval, este personaje juega un papel secundario comparado con el del « torito de petate », es decir una figura hecha de cartón adornada abundantemente, en torno de la cual se realizan danzas que evocan la relación del ser humano con el toro.

3. En su estudio sobre la danza purépecha de viejos, García Mora (2011, p. 28) observa que « los viejitos hacen el papel de pastores significando de este modo que conducen la grey cristiana a Charapan [...] Es por eso que no se trata de una mera representación teatral, es un rito anual durante el cual el poblado se transforma en un sitio donde los sucesos relatados en los evangelios tienen lugar de nuevo ».

4. Salvo quizá una o dos excepciones, a las mujeres no se les permite interpretar el papel de los diablos principales. En la actualidad algunas muchachas osan meterse en las cuadrillas de los diablos «secundarios", pero lo hacen ocultando su identidad femenina. Por lo general la participación femenina en las pastorelas sigue consistiendo en interpretar los papeles de pastoras o de rancheras, aunque la migración masculina conduce cada vez más a flexibilizar esta regla.

5. Motolinía atestiguó que en la obra La tentación de Cristo, que es típica del teatro de evangelización en lengua náhuatl, Lucifer se disfraza de ermitaño, pero « no puede ocultar [...] los cuernos y las uñas que de cada dedo, así de las manos como de los pies, le salían » (Horcasitas 1974, pp. 133-134).

6. Véase el cuestionamiento crítico de Dehouve (2006) al llamado « sistema de cargos ».

7. La concepción de performance que Goody cuestiona fue expresada por Turner en estos términos: «por sus performances las conoceráis [...] las culturas se expresan más completamente en sus performances rituales y teatrales y gracias a ellas adquieren conciencia de sí mismas [...] (Schechner 2000, p. 16).

8. De entre los diez libretos que me proporcionaron en diferentes poblados, sólo tres confirman tal afirmación por el tipo de papel, el estilo de escritura y la caligrafía. Habría que continuar indagando al respecto en futuros trabajos.

9. Nurite o nureten (Satureja macrostema) es el nombre de una planta que crece en la sierra y a la que los purépechas otorgan mucha importancia, atribuyéndole propiedades afrodisiacas y medicinales (cura malestares estomacales), por lo que se toma como té. También es usada para decorar diferentes espacios rituales.

10. Género de música instrumental que se ejecuta con orquesta de cuerdas o con banda de viento. Algunos autores interpretan que la palabra « abajeño » deriva de la expresión « son [o música] de allá abajo ", en alusión a la que se toca en las tierras bajas de Michoacán, en la tierra caliente, la costa (Chamorro 2002, p. 178). El tempo rápido del abajeño se acompaña con pasos de baile con carácter fuerte y preciso.

11. Esta práctica parece haberse arraigado en bases muy antiguas. En una muy breve crónica del siglo Xvi sobre Los Tres Reyes de Cuernavaca (1535 ó 1540), un dato sugiere que con esta representación teatral asistimos a la escenificación de sucesos de actualidad. En dicha crónica se hace constar que « aquí ponemos que en nuestro entero juicio vimos el primer nexcuitili y ejemplo porque un demonio tentaba a los cristianos, y entonces lo conjuraron para que no se apoderara de las almas y así havéis de hacer vosotros los que quedáis en el mundo, y para que nos acordemos de la Pasión de Christo Nuestro 
Señor, que no es juguete, lo ponemos aquí para acordarnos cómo murió Christo, así se ha de ir continuando en lo que adelante, y para que sepáis cómo se puso la estrella que guió a los tres Reyes magos cuando fueron a visitar a Nuestro Señor » (Ms. en lengua náhuatl conservado en la BNF, trad. del padre José Pichardo en Horcasitas 1974, p. 251). En este nexcuitilli ya no solamente se representa escénicamente un pasaje de la Biblia, sino una situación vivida, la cual se puso en escena con objeto de provocar un cierto efecto, en este caso conjurar al demonio. ¿Acaso la pastorela siga desempeñando esa función - « combatir el mal y purificar el ambiente » (ibid.) - que durante las primeras décadas de la colonización, cumplió el teatro?

12. Los comentarios que en adelante citaré me fueron confiados por cuatro varones adultos durante una convivencia familiar. Que me sea permitido preservar el anonimato de éstos, omitir el nombre del lugar y de la fecha, para no defraudar su confianza o poner en riesgo su seguridad; de no hacerlo, ellos podrían ser involucrados en los hechos de violencia que se narran.

\section{REFERENCIAS CITADAS}

Aracil Beatriz, Alejandro OrTIZ y Oscar Armando GARcía

2004 Fiesta y teatralidad de la pastorela mexicana, Universidad Nacional Autónoma de México, col. « Paideia », México.

Araiza Elizabeth

2013 «El arte de actuar varias realidades particulares. Notas para un estudio antropológico de las pastorelas del territorio purépecha », Relaciones, 135 (34), pp. 181-218.

BAUMAN Richard y Pamela Ritch

1994 «Informing performance: producing the Coloquio in Tierra Blanca », Oral tradition, 9 (2), pp. 255-280.

Chamorro Arturo

1994 Sones de la guerra. Rivalidad y emoción en la práctica de la música p'urepecha, Colegio de Michoacán, col. « Investigaciones », Zamora.

2002 "Orquesta de Quinceo » in Julio Herrera (ed.), Cinco décadas de investigación sobre música y danza indígena, Instituto Nacional Indigenista, México, vol. 1 , pp. 175-184.

Dehouve Danièle

2006 Essai sur la royauté sacrée en République mexicaine, CNRS Éditions, París.

DíAz Cruz Rodrigo

1998 Archipiélagos de rituales. Teorías antropológicas del ritual, Antropos Editorial, Barcelona.

2004 «L'exploration de la distance: idolâtries, superstitions, résistances rituelles » in Ahmed Ben Naoum et al. (eds.), Les formes de reconnaissance de l'autre en question, Presses Universitaires de Perpignan, col. "Études », Perpignan, pp. 397-415.

García Mora Carlos

2011 «Los viejos y la implantación de la creencia en el país purépecha », [http://carlosgarciamoraetnologo.blogspot.com, consultado el 25/11/2012]. 
GooDY Jack

2001 Representaciones y contradicciones. Ambivalencias y contradicciones hacia las imágenes, el teatro, la ficción, las reliquias y la sexualidad, Ariel, Barcelona.

HENRÍQuez Patricia

2008 «De la escena ritual a la teatral en una obra de teatro indígena prehispánico: Rabinal Achí o Danza del Tun », Aisthesis, 44, pp. 67-81.

HersKovits Melville J.

1976 El hombre y sus obras, Fondo de Cultura Económica, México [1948].

Hijar Ornelas Tomás de

2008 Pastorelas de Jalisco. Antecedentes, desarrollo y pervivencia de los coloquios de pastores en el Occidente de México, Secretaría de Cultura del Estado de Jalisco, México.

Horcasitas Fernando

1974 El teatro náhuatl. Época novohispana y moderna, UNAM, Instituto de Investigaciones Históricas, México.

Houseman Michael

2003 "Vers un modèle anthropologique de la pratique psychothérapeutique », Thérapie familiale, 24 (3), pp. 289-312.

2008 "Relations rituelles et recontextualisation », in Haruka Wazaki (ed.), Multiplicity of meaning and the interrelationship of the subject and the object in ritual and body texts, Nagoya University, Nagoya, pp. 109-114 [http://halshs.archives-ouvertes.fr/halshs-00445620, consultado el 08/11/2012].

2012 Le rouge est le noir, Presses Universitaires du Mirail, Toulouse.

Houseman Michael y Carlo Severi

$1994 \quad$ Naven ou le donner à voir. Essai d'interprétation de l'action rituelle, CNRS Éditions/Éditions de la Maison des sciences de l'homme, París.

KoRSBAEK Leif

1996 Introducción al sistema de cargos (Antología), UNAM, Toluca/México.

LASSÈGUE Jean

2003 «Ritualisation et culture », Séminaire Formes symboliques, 4 de marzo de 2003 [http://www.formes-symboliques.org, consultado el 26/11/2012].

LEIRIS Michel

1958 La possession et ses aspects théâtraux chez les Éthiopiens de Gondar, Plon, París.

MARIN Louis

1994 De la représentation, Gallimard/Le Seuil, col. « Hautes études », París.

MÁrquez Carlos F.

2005 «Las pastorelas, vinculación de lo divino con lo cotidiano y de lo social con lo político ", in La Jornada Michoacán, lunes 26 de diciembre de 2005, Sección Rayuela, II y última, p. 14. 


\section{Monod BeCquelin Aurore y Alain BRETON}

2002 La Guerre Rouge ou une politique maya du sacré. Un carnaval tzeltal au Chiapas, Mexique, CNRS Éditions, París.

OSEguera Andrés

2008 « De ritos y antropólogos. Perspectivas teóricas sobre el ritual indígena en la antropología realizada en México », Cuicuilco, 15 (42), pp. 97-118.

RAPPAPORT Roy A.

2001 Ritual y religión en la formación de la humanidad, Cambridge University Press, Madrid.

Romero SALINAS Joel

1984 La pastorela mexicana, origen y evolución, Fondo Nacional para el Fomento de las Artesanías, México.

SCHECHNER Richard

2000 Performance. Teoría y prácticas interculturales, Universidad de Buenos Aires, Buenos Aires.

2003 Performance Theory, Routledge, Londres/Nueva York [1988].

TARABOUt Gilles

1998 «Des gags dans le culte. Remarques sur la bouffonnerie rituelle au Kérala », in Line Bansat-Boudon (ed.), Théâtres indiens, École des hautes études en sciences sociales, París, pp. 269-299.

Topete LaRa Hilario

2005 «Variaciones del sistema de cargos y la organización comunitaria para el ceremonial en la etnorregión purépecha », Cuicuilco, 12 (34), pp. 95-129.

2011 «Danza y parafernalia. Sentidos desvelados en la danza de Kurpitiecha en la Meseta purépecha del occidente de México », Diálogo andino, 38, pp. 135-148. 